\title{
Path Analysis of the Relationship Between Optimism, Humor, Affectivity, and Marital Satisfaction Among Infertile Couples
}

\author{
Shahla Ostovar ${ }^{1} \cdot$ Mark D. Griffiths $^{2}$ (D) Tayebeh Raeisi $^{3}$. \\ Intan Hashimah Mohd Hashim ${ }^{1}$
}

Published online: 3 July 2020

(C) The Author(s) 2020

\begin{abstract}
Marital satisfaction is an important factor for establishing a family relationship, feeling satisfied, and living happily together. The aim of the present study was to investigate the relationship between optimism, humor, positive and negative affect, and marital satisfaction among infertile couples. The sample comprised 80 infertile Iranian couples $(n=160)$ who visited infertility clinics. Participants completed a series of Persian versions of psychometric scales related to optimism (Attributional Style Questionnaire), humor (Humor Styles Questionnaire), marital satisfaction (Enrich Marital Satisfaction Questionnaire), positive affect (PA) and negative affect (NA) (Positive and Negative Affect Schedule). The obtained result of Smart PLS statistical analysis confirmed the significant positive correlation between optimism and humor with marital satisfaction and high PA and low NA. Moreover, the findings also provided an adequate fit of the model. The findings demonstrated that infertile couples high in optimism and humor have higher levels of marital satisfaction and high PA and low PA. Based on the study's findings, interventions for facilitating optimism and humor among infertile couples are discussed.
\end{abstract}

Keywords Optimism $\cdot$ Humor $\cdot$ Positive affect $\cdot$ Negative affect $\cdot$ Infertility $\cdot$ Marital satisfaction

Marital satisfaction is the degree to which couples feel content regarding specific aspects of marital relationship (Vizheh et al. 2013; Zaheri et al. 2016), and is an important factor for establishing a family relationship, feeling satisfied, and living happily together (Shakerian 2010). However, marital satisfaction cannot be easily established. Adult attachment theory

Mark D. Griffiths

mark.griffiths@ntu.ac.uk

1 School of Social Sciences, Universiti Sains Malaysia, 11800, Minden, Penang, Malaysia

2 Psychology Department, Nottingham Trent University, Burton Street, Nottingham NG1 4FQ, UK

3 Psychology Department, Shahrood Branch, Islamic Azad University, Shahrood, Iran 
offers a promising conceptual framework for understanding the psychological and contextual factors that contribute to marital satisfaction (Granqvist 2014). Attachment research has established an association between adult attachment and marital satisfaction (Abbasi et al. 2016; Kobak and Hazan 1991; Vollmann et al. 2019). Among several factors, infertility is one of the factors that can negatively affect marital relationships (Hussein 2014). Infertility has been defined as a couple's inability to conceive that can occur after one or more years of being sexually active (Harzif et al. 2019; Lindsay and Vitrikas 2015; Sami et al. 2012).

Worldwide, infertility is estimated to affect between 8 and $12 \%$ of reproductive-aged couples, with $9 \%$ currently cited as the probable global average (Inhorn and Patrizio 2015). In some regions of the world, the rates of infertility are much higher in some populations (Inhorn and Patrizio 2015; Vander Borght and Wyns 2018). A report issued by World Health Organization (WHO) reported that infertility can impair emotional, spiritual, and psychological well-being of couples, and can lead to physical, gynecologic, and biopsychosocial health problem (Forooshany et al. 2014; Luk and Loke 2014). Many studies have revealed the psychological, physical, emotional, sociocultural, and financial problems of infertility (Mahadeen et al. 2018; Nasim et al. 2019). Infertile couples demonstrate signs of depression, anxiety, social labelling, fear, loss of social status, guilt feeling, despondence, stress, and financial hardships (Nasim et al. 2019). Infertile couples often choose to hide such issues and avoid sharing their problem with their families and relatives, which then leave them unsupported. Over the course of time, avoidance may result in social isolation (Hasanpoor et al. 2014). This potentially serious issue is a factor in many problems and disorders (Macaluso et al. 2008). Infertile couples experience less marital satisfaction than fertile counterparts (Roudsari and Bidgoli 2017) and are afraid of losing their partners (Foroozanfard and Sadat 2013). It has been reported that $25 \%$ of Iranian couples experience infertility at some stage during their marital life (Hasanpoor et al. 2014; Vahidi et al. 2009). According to the WHO (2009), it is time to go beyond diagnosis and clinical interventions related to infertile couples and to focus on the psychological factors associated with fertility problems and improving the quality of life for infertile individuals. A careful perusal of literature shows that optimism and humor play a key role in infertile couples' marital life and their positive and negative emotions and feelings (Ghadami and Khalatbari 2015; Gorman and Jordan 2015; Hills and Argyle 2001; Safari 2016; Saroglou et al. 2010).

\section{Optimism, Marital Satisfaction, Positive Affect, and Negative Affect}

Optimism is one of the most important dispositional factors that contributes to positive outcomes in life, including marital satisfaction (Scheier and Carver 1985). It is defined in terms of the explanatory styles of individual (Seligman 2006). Several studies in the field of well-being have confirmed that optimistic people experience more marital satisfaction (Homaei et al. 2016). Psychological theories and studies concerning life satisfaction have conceptualized optimism with life satisfaction and the expectation of a better future (Mirahmadi 2009) and can be a predictor of a couple's marital quality (Homaei et al. 2016; Smith et al. 2013b). Findings from earlier studies on couples' understanding of life show that positive traits such as optimism have an important effect on long-term marital satisfaction among couples (Ko et al. 2007; Turliuc and Candel 2017), and enhance intimacy (Sabouripour and Roslan 2015). There is evidence that individuals with high optimism experience higher levels of marital satisfaction (Clark and Schroth 2010) and lower levels of mental and emotional problems (Homaei et al. 2016; Noori and Biria 2009; Poursardar et al. 2012). 


\section{Humor, Marital Satisfaction, Positive Affect, and Negative Affect}

Research also indicates that humor is positively correlated with overall health, professional success, and perseverance (Martin and Ford 2018). Humor is one of the individual factors that plays a key role in quality of marital relationships (Gharibi et al. 2016; Rostami et al. 2016), positive affect (PA), and negative affect (NA). Researchers have long been interested in the relationship between humor and psychological well-being (Cann and Collette 2014; Luk and Loke 2014; Martin et al. 2003). Some researchers report that more than nine-tenths of couples believe that sense of humor promotes marital satisfaction and relationship positively (Safari 2016). A study by Ziv and Gadish (1989) investigated the relationship between humor and marital satisfaction and reported a positive correlation between wives' marital satisfaction and their spouses' sense of humor. Happiness is also positively correlated with a sense of humor (Ford et al. 2016; Liu 2012).

Attachment style theory (Bowlby 1969, 1973, 1979, 1980) was developed to explain social development "from the cradle to the grave" (Bowlby 1979; p. 129). Recent studies have highlighted that attachment styles have a strong relationship with optimism, humor, marital satisfaction, PA, and NA (Mardani Hamule and Heidari 2010). Research in these areas demonstrate that individuals with safe attachment styles have healthier relationships with others and particularly with their spouses (Raeisipoor et al. 2012). Following from this perspective, the present authors propose that optimism and humor are formative in marital satisfaction and affective mood states. To our knowledge, no studies have ever been carried out on infertile couples investigating the relationship between both optimism and humor in marital satisfaction and affect mood states. The present study addresses this gap in the literature. The aim of the present study was to investigate the role of these two positive psychological constructs (i.e., optimism and humor) in marital satisfaction and affective mood state (positive and negative) among infertile couples, and develop a model demonstrating these multiple relationships.

Bowlby's (1973) theory of adult attachment style was used to provide a theoretical framework for the present study. Current researchers believe that dimensional measures of attachment are more appropriate (Cassidy et al. 2013) because they capture attachment characteristics in a continuous measure that is a more precise measure of each couple member (Parra et al. 2017). Based on this theoretical position and empirical evidence discussed above, the conceptual framework of the present study is illustrated in Fig. 1. This shows optimism and humor as predictor variables of marital satisfaction and affective mood state based on research outlined in previous studies (Mikulincer et al. 2003; Moghadam et al. 2016).

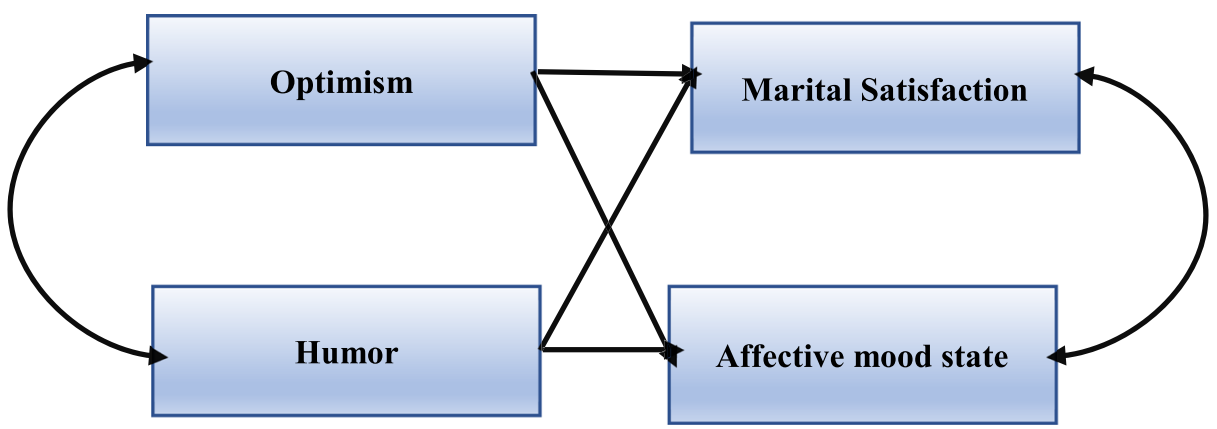

Fig. 1 Conceptual model of the present study examining the relationship between optimism, humor, affective mood state, and marital satisfaction 
In investigating the relationships between optimism, humor, affective mood state, and marital satisfaction among infertility couples, the following hypotheses were formulated:

1. Higher levels of optimism will play a significant role in marital satisfaction among infertile couples.

2. Higher levels of optimism will be positively related with high PA and low NA among infertile couples.

3. Humor will be positively related with marital satisfaction among infertile couples.

4. Humor will play a significant role in affective mood state among infertile couples.

\section{Methods}

\section{Participants, Procedure, and Ethics}

In the present study, 160 Iranian participants ( 80 women; 80 men) were surveyed who visited infertility clinics. Iranian clinics that had at least $10-15$ couples per infertility clinic were randomly selected. In the present study, all participants were invited to participate on a voluntary basis and they signed a short consent form before a survey booklet was given to them. Couples were interviewed one-on-one and were asked to complete the booklet (taking approximately $25 \mathrm{~min}$ to complete). The participants' age ranged from 20 to 49 years $(M=$ 32.05 years, $\mathrm{SD}=2.1$ ). The wives' age ranged from 20 to 43 years (mean $=31.06$ years, $\mathrm{SD}=$ 5.43 ) and the husbands' age ranged from 26 to 49 years (mean $=35.14$ years, $\mathrm{SD}=6.24)$. A total of $10 \%$ had high school education $(n=16), 44.2 \%$ had a Bachelor's degree $(n=71), 28 \%$ had a Master's degree $(n=46)$, and $17.8 \%$ provided no response $(n=27)$. Ethical approval was granted by the research team's university ethics committee.

\section{Materials}

The assessment tools comprised five scales.

Marital Satisfaction Questionnaire (ENRICH) ENRICH (evaluation and nurturing relationship issues, communication, and happiness) was developed by Fowers and Olson (1993) to assess marital satisfaction. Originally, it comprised 115 items and 12 subscales. The revised version comprises 47 items and nine subscales: conflict resolution, marital relationship, leisure activities, financial management, sexual relationship, family and friends, children and parenting, personality issues, and religious orientation. Answers are given on 5-point Likert scale $(1=$ completely agree and $5=$ completely disagree $)$. Each item is relevant to one of the important areas in marital satisfaction and can be used as a diagnostic instrument for couples to improve their relationship and quality of life. The internal consistency reliabilities $(\alpha$ coefficient) of the scale has been demonstrated in previous studies (Mobarak Abadi et al. 2014). In the present study, the reliability of the whole scale was 0.89 .

Humor Styles Questionnaire Martin et al. (2003) developed the Humor Styles Questionnaire (HSQ) to assess four humor styles (two other-directed and two self-directed). Eight items assess each humor style and the responses are provided using a 7-point Likert scale $(1=$ totally disagree to $7=$ totally agree). Previous studies have shown that HSQ has good construct 
validity and internal consistency ranging from 0.77 to 0.81 (Martin et al. 2003). In the present study, the Persian version of the HSQ was used (Alinia et al. 2009). For the present study, the Cronbach alphas were 0.72, (affiliative humor), 0.80 (self-enhancing humor), 0.73 (aggressive humor), and 0.71 (self-defeating humor).

Attributional Style Questionnaire The Attributional Style Questionnaire (ASQ) was developed by Peterson et al. (1982). It is most commonly used to assess individuals' explanatory style. The ASQ assesses optimism by utilizing six negative and six positive life situations' outcomes. Each scenario is followed by two explanations and participants are asked to select one of them. The ASQ comprises three factors: stability of time (stable vs. unstable), global effect (vs. specific), and internal (vs. external). It has 12 hypothetical situations. Six are positive and six are negative and the individual writes down a single cause for each event. Half of them are interpersonal/affiliative and the other half are achievement-related. High scores on the attributional style for negative outcomes reflect high ratings of attribute (Peterson et al. 2009; Sohl et al. 2011). The internal consistency reliabilities of the ASQ were 0.44-0.69 (Peterson et al. 1982; Smith et al. 2013a). The Persian ASQ scale (Ashkani and Heydari 2014) showed a good degree of internal consistency (0.80). The scale in the present study had acceptable to good Cronbach alphas rating from 0.69 to 0.74 .

The Positive and Negative Affect Schedule Watson et al. (1988) developed a self-report to assess two broad domains of affect. The scale comprises two different 10-item scales assessing positive affect (items 1, 3, 5, 9, 10,12,14, 16, 17, and 19 including strong, proud, and interested) and negative affect (items 2, 4, 6, 7, 8, 11, 13, 15, 18, and 20 including afraid, ashamed, and nervous). Low NA scores reflect "calmness and serenity" whereas high NA scores suggest "subjective distress and unpleasurable engagement." Low PA scores reflect "sadness and lethargy" whereas high PA scores reflect "high energy, full concentration, and pleasurable engagement" (Watson et al. 1988). It uses a 5-point Likert scale (ranging from $1=$ very slightly or not at all to $5=$ very much or extremely), where higher scores indicate a higher level of valence of the mood descriptors. Many studies (Beltrán-Morillas et al. 2019; Wróbel et al. 2019) have demonstrated good internal consistency for both positive affect ( $\alpha=0.86$ to $0.90)$ and negative affect ( $\alpha=0.84$ to 0.87 ). Test-retest reliability was reported as 0.79 and 0.81 for positive and negative affect respectively, after one week (Watson et al. 1988). In the present study, the Persian version demonstrated good internal consistency. For positive affect, the Cronbach's $\alpha$ was 0.78 and for negative affect it was 0.76 .

\section{Statistical Analysis}

The Statistical Package for the Social Sciences (SPSS; SPSS Inc., Chicago, IL, USA) version 21.0 was used. The research hypotheses were assessed by using PLS-SEM to assess the measurement and structural model, and to perform Multigroup Analysis (MGA) using SmartPLS 3.0 (Hair et al. 2019; Ringle et al. 2015). SEM second generation of statistical methods were chosen for simultaneously testing and estimating the relationship in each of the multiple independent and dependent constructs (i.e., measurement of the models).

The research team analyzed the two-step approach during which the measurement models (first-order and second-order constructs) were examined (see Table 1 and Table 2). In order to establish the second-order constructs, a two-stage approach was used, with the first stage 
Table 1 Results of the measurement model for first-order constructs

\begin{tabular}{|c|c|c|c|c|c|c|}
\hline Construct & Components & $\begin{array}{l}\text { Loadings items } \\
\text { min-max }\end{array}$ & Loading components & $\mathrm{AEV}$ & $\mathrm{CR}$ & Cronbach's alpha \\
\hline \multirow[t]{7}{*}{ ASQ } & & & & 0.753 & 0.948 & 0.875 \\
\hline & P-Stability & $0.75-0.90$ & 0.850 & & & \\
\hline & P-Globality & $0.80-0.88$ & 0.883 & & & \\
\hline & P-Internal & $0.83-0.91$ & 0.912 & & & \\
\hline & N-Stability & $0.68-0.94$ & $0.784^{\circ}$ & & & \\
\hline & N-Globality & $0.89-0.93$ & 0.869 & & & \\
\hline & N-Internal & $0.82-0.89$ & 0.901 & & & \\
\hline \multirow[t]{5}{*}{ HSQ } & & & & 0.773 & 0.931 & 0.863 \\
\hline & Affiliative & $0.72-0.94$ & 0.960 & & & \\
\hline & Self-enhancing & $0.63-0.86$ & 0.703 & & & \\
\hline & Aggressive & $0.81-0.90$ & 0.952 & & & \\
\hline & Self-defeating & $0.76-0.89$ & 0.878 & & & \\
\hline \multirow[t]{10}{*}{ ENRICH } & & & & 0.926 & 0.977 & 0.872 \\
\hline & Conflict resolution & $0.82-0.93$ & 0.887 & & & \\
\hline & Marital relationship & $0.80-0.88$ & 0.971 & & & \\
\hline & Leisure activities & $0.74-0.82$ & 0.933 & & & \\
\hline & Financial management & $0.78-0.90$ & 0.906 & & & \\
\hline & Sexual relationship & $0.82-0.86$ & 0.971 & & & \\
\hline & Family and friends & $0.66-0.84$ & 0.845 & & & \\
\hline & Children and parenting & $0.81-0.92$ & 0.938 & & & \\
\hline & Personality issues & $0.79-0.95$ & 0.726 & & & \\
\hline & Religious orientation & $0.83-0.88$ & 0.890 & & & \\
\hline \multirow[t]{3}{*}{ PANAS } & & & & 0.690 & 0.814 & 0.858 \\
\hline & Positive affect & $0.89-0.96$ & 0.931 & & & \\
\hline & Negative affect & $0.70-0.83$ & 0.716 & & & \\
\hline
\end{tabular}

a Average variance extracted $(\mathrm{AVE})=($ summation of the square of the factor loadings $) /($ summation of the square of the factor loadings $)+$ (summation of the error variances). ${ }^{b}$ Composite reliability $(\mathrm{CR})=($ square of the summation of the factor loadings)/ (square of the summation of the factor loadings) + (square of the summation of the error variances)

involving an assessment of the measurement model to establish the second-order constructs (Ali et al. 2018). The present study includes the reflective constructs model second-order constructs. The reflective constructs model was calculated and interpreted in two stages: (i) the evaluation of the validity and reliability of the measurement model, and (ii) the evaluation of the structural model. The measurement model is used for showing the relationships between each observable variable and underlying constructs. The PLS-SEM is fit for the measurement of models inclusive of reflective constructs (Ali et al. 2018).

A sample size of 160 Iranian participants ( 80 women; 80 men) who visited infertility clinics would generally be seen as adequate for a PLS-SEM analysis, with previous studies indicating a necessary threshold of 100 participants (Reinartz et al. 2009). Moreover, calculating the minimum sample size, based on statistical power, suggests that the sample size was more than adequate (Sarstedt et al. 2017). G*Power was applied to calculate the minimum sample size based on statistical power (Faul et al. 2009). To gain power of 0.8 for analysis, which is good for social science, a minimum sample size of 40 is needed. Therefore, the present study had an adequate sample size to perform the analysis. Data were analyzed using partial least squares structural equation modeling (PLS-SEM) using the Smart PLS 3.0 software (Ringle et al. 2015). Internal reliability was calculated using Cronbach's alpha and composite reliability (CR). 
Table 2 Results of the measurement model after creating second-order constructs

\begin{tabular}{|c|c|c|c|c|c|}
\hline Construct & Components & Loading & Type of Construct & AVE & CR \\
\hline \multirow[t]{7}{*}{ ASQ } & & & Reflective & 0.753 & 0.948 \\
\hline & P-Stability & 0.850 & & & \\
\hline & P-Globality & 0.881 & & & \\
\hline & P-Internal & 0.913 & & & \\
\hline & N-Stability & $0.786^{\prime}$ & & & \\
\hline & N-Globality & 0.869 & & & \\
\hline & N-Internal & 0.892 & & & \\
\hline \multirow[t]{5}{*}{ HSQ } & & & Reflective & 0.773 & 0.931 \\
\hline & Affiliative & 0.962 & & & \\
\hline & Self-enhancing & 0.710 & & & \\
\hline & Aggressive & 0.953 & & & \\
\hline & Self-defeating & 0.878 & & & \\
\hline \multirow[t]{10}{*}{ ENRICH } & & & Reflective & 0.926 & 0.978 \\
\hline & Conflict resolution & 0.884 & & & \\
\hline & Marital relationship & 0.971 & & & \\
\hline & Leisure activities & 0.932 & & & \\
\hline & Financial management & 0.906 & & & \\
\hline & Sexual relationship & 0.960 & & & \\
\hline & Family and friends & 0.829 & & & \\
\hline & Children and parenting & 0.938 & & & \\
\hline & Personality issues & 0.719 & & & \\
\hline & Religious orientation & 0.890 & & & \\
\hline \multirow[t]{3}{*}{ PANAS } & & & Reflective & 0.690 & 0.807 \\
\hline & Positive affect & 0.907 & & & \\
\hline & Negative affect & 0.740 & & & \\
\hline
\end{tabular}

\section{Results}

\section{Measurement Model}

The Cronbach's alpha values of each construct were above 0.7 (ranging from 0.858 to 0.872 ) which suggests a high level of internal reliability (Fornell and Larcker 1981). Following this, for items with loadings from 0.5 to 0.7 , it is necessary to cross-check with their composite reliability (CR) and average variance extracted (AVE). If CR and AVE meet the threshold, these items can be retained. The CR criteria were applied to measure the $\mathrm{CR}$ or internal consistency (IC) of the latent variables, and must be higher than 0.7 to demonstrate IC (Sarstedt et al. 2017). The CR scores were all above 0.8, ranging from 0.818 to 0.977 , suggesting that the composite measurement items had sufficient reliability (see Table 1).

To empirically and statistically assess reflective measurement items and constructs (Table 2), the study examined the outer/item loadings and composite reliability (CR). The minimum cutoff criterion for the indicator's outer loadings is 0.5 (Hair et al. 2011). First-order outer constructs were conducted for all items and dimensions. The values of all first-order constructs were higher than 0.7 indicating the establishment of internal consistency for all involved reflective constructs. All of the aforementioned findings guarantee the reliability of the model. The validity of the model was measured based on convergent and discriminant validities. All constructs showed AVE values greater level than the 0.5 thresholds, ranging from 0.690 to 0.926 , confirming convergent validity (see Table 2). 


\section{Structural Model}

After measurement items were assessed and found as valid and reliable, the next stage assessed and evaluated structural model relationships. The six dimensions became the observed indicators of the optimism construct, and four dimensions indicators of humor, and then the full structural model was run to evaluate the structural model results (Albort-Morant et al. 2016). Additionally, the two-stage approach provided "the advantage of estimating a more parsimonious model on the higher level analysis without needing the lower order constructs" (Becker et al. 2012, p. 366). More specifically, mode A measurement was used for two reasons. On the theoretical level, reflective constructs were used, suggesting the constructs explain all indicators simultaneously (Becker et al. 2013). The PLS literature indicates that reflective measurements are usually associated with mode A when following the two-stage approach (Becker et al. 2012). On the measurement level, this implies that proxies are created for the reflective latent construct that is subjected to analysis in PLS mode A.

Table 3 and Fig. 2 show the results of the structural model assessment and the MGA results for hypothesis testing. Using these analyses, all four hypotheses were confirmed: (i) higher levels of optimism played a significant role in marital satisfaction among infertile couples; (ii) humor was positively related with marital satisfaction among infertile couples; (iii) higher levels of optimism were positively related with high PA and low NA among infertile couples; and (iv) humor played a significant role with high PA and low NA among infertile couples. Table 3 shows the results of standardized path coefficient and $t$ tests. This shows that optimism at $99 \%$ had a significant positive impact upon marital satisfaction and affectivity variables. Humor at $99 \%$ had a significant positive impact upon marital satisfaction and affectivity variables. Performing the PLS-SEM algorithm, estimates are obtained for the structural model relationships that imply the hypothesized relationships between the research constructs, the assessment of the level of the $R^{2}$ values, and $f^{2}$ effect size (Table 3). The $R^{2}$ value higher than 0.2 is considered high. In the present study, the $R^{2}$ values are considered high and acceptable (Hair et al. 2017). In addition, the findings show positive and significant effects among infertile couples.

The present study also followed the recommendation of testing the correlations between constructs (Gholami et al. 2013). Table 4 shows the inter-correlation values of the constructs and their measure in the model. Table 4 shows that all correlation values indicated adequate discriminant validity (Fornell and Larcker 1981). Therefore, the present study ensured that all measurement model criteria were met and supported the measures' reliability, convergent validity, and discriminant validity. Fornell-Larcker and heterotrait-monotrait (HTMT) criteria were applied for discriminant validity (Voorhees et al. 2016). The results in Table 5 confirm the discriminant validity in the examined constructs. Several studies have reported that acceptable HTMT values can be lower than either 0.85 or 0.9 . The present study adopted the more

Table 3 Examining the main hypotheses of the research

\begin{tabular}{|c|c|c|c|c|c|c|c|}
\hline Hypotheses & Path & $\beta$ & $t$ & $f^{2 \mathrm{c}}$ & $p$ value & $R^{2}$ & Results \\
\hline H1 & $\mathrm{OPT} \rightarrow \mathrm{MAS}$ & 0.37 & $4.8 * *$ & 0.32 & 0.001 & 0.578 & Accepted \\
\hline $\mathrm{H} 2$ & $\mathrm{OPT} \rightarrow \mathrm{MH}$ & 0.24 & $3.1 * *$ & 0.20 & $<0.001$ & 0.615 & Accepted \\
\hline H3 & HUM $\rightarrow$ MAS & 0.33 & $3.6^{* *}$ & 0.28 & $<0.001$ & 0.489 & Accepted \\
\hline $\mathrm{H} 4$ & $\mathrm{HUM} \rightarrow \mathrm{MH}$ & 0.41 & $5.2 * *$ & 0.36 & $<0.001$ & 0.396 & Accepted \\
\hline
\end{tabular}

$f^{2 \mathrm{c}}=\left(R^{2}\right.$ include $-R^{2}$ exclude $) /\left(1-R^{2}\right.$ includ $)$ 


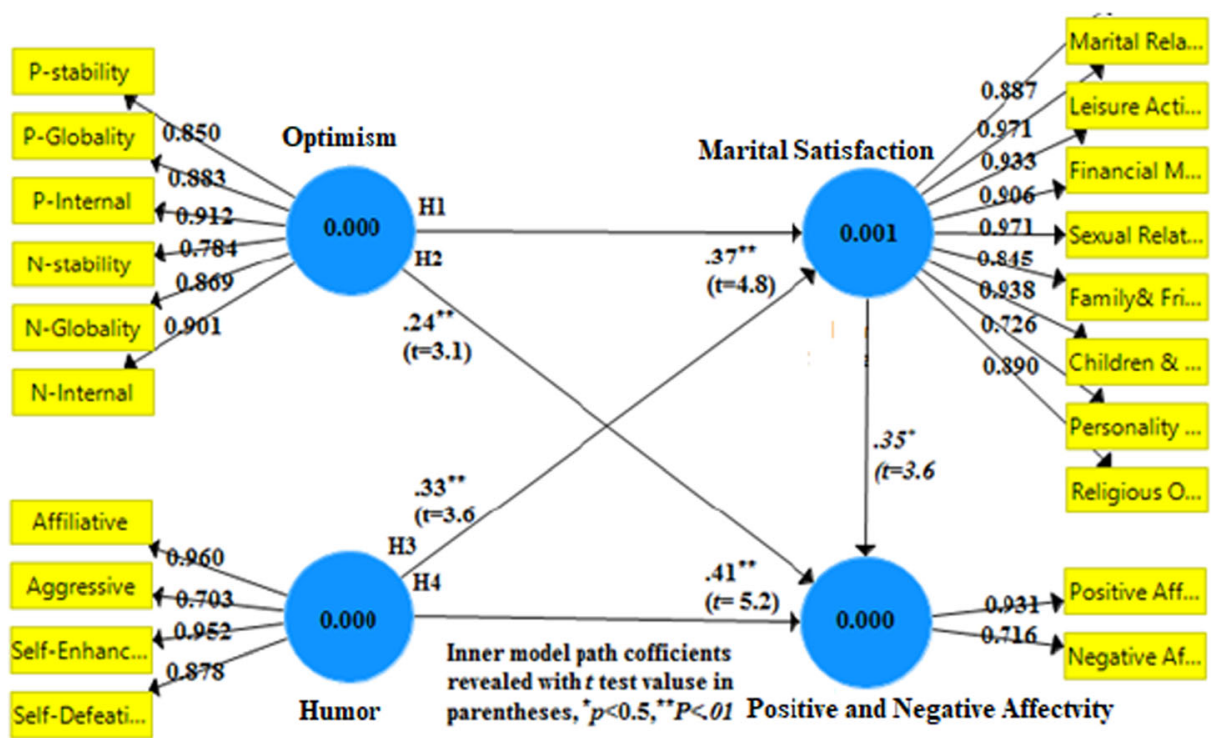

Fig. 2 Results of PLS measurement and structural models with significant coefficients ( $t$-value)

rigorous HTMT of 0.85 , indicating discriminant validity was established (Henseler et al. 2015).

The Fornell-Larcker criteria were met and some of the indicators are slightly high, which is normal in the evaluation of variance-based SEM. Therefore, there is discriminant validity between the research constructs (see Table 6).

\section{Discussion}

Infertility is a complex and social crisis that can affect individuals, family, and society. It also has serious implications for the mental health and well-being of those involved. The present study provides important evidence of factors that influence marital satisfaction and affectivity among infertile couples. Couples with infertility problems face higher levels of emotional and mental health concerns. Couples characterized as having low perceived social support and have significantly a wide range of depressive symptoms (Ahmadi et al. 2011) and anxiety symptoms (Nasim et al. 2019). To date, no previous study has ever examined the combination of the variables of optimism and humor upon levels of marital satisfaction and affectivity among infertile couples. Starting from a theoretical construction based on relevant literature,

Table 4 Mean, standard deviations (SDs), and correlations of constructs

\begin{tabular}{|c|c|c|c|c|c|c|}
\hline Construct & Mean & SD & ASQ & HSQ & ENRICH & PANAS \\
\hline ASQ & 4.71 & 1.26 & $0.82 *$ & & & \\
\hline HSQ & 4.16 & 1.28 & 0.52 & $88^{*}$ & & \\
\hline ENRICH & 4.41 & 1.19 & 0.61 & 0.73 & $92 *$ & \\
\hline PANAS & 4.52 & 1.21 & 0.32 & 0.44 & 0.56 & $94 *$ \\
\hline
\end{tabular}

*Square root of the AVE on the diagonal 
Table 5 Discriminant validity using heterotrait-monotrait criteria

\begin{tabular}{lllll}
\hline Construct & ASQ & HSQ & ENRICH & PANAS \\
\hline ASQ & & & & \\
HSQ & 0.441 & & & \\
ENRICH & 0.384 & 0.470 & & \\
PANAS & 0.326 & 0.298 & 0.601 & \\
\hline
\end{tabular}

the present study examined a specific model to explain the relationship of optimism and humor (predicting variables) on marital satisfaction and affectivity (criteria variables) using data from infertile couples.

The findings in the present study are in accordance with previous research that has found decreased marital communication as a result of infertility-related stress (Gana and Jakubowska 2016). The model here, simultaneously tested the relationship of optimism and humor upon marital satisfaction and affectivity among infertile couples, confirming the psychological and theoretical basis for the significant relationship between these variables. The findings of higher scores in optimism and also higher percentage of humor styles, compared with those of the marital satisfaction and high PA and low NA, are similar to those found in the extant literature (Ford et al. 2016; Safari 2016).

The first hypothesis (H1) that optimism would predict more marital satisfaction was supported (i.e., there was a positive and significant relationship between optimism and marital satisfaction among infertile couples). The second hypothesis (H2) that there would be a significant relationship between optimism and high PA and Low NA was also supported (i.e., there was a positive and significant relationship between optimism, high PA, and low NA among infertile couples). The third hypothesis (H3) was that humor would be significantly associated with marital satisfaction was supported in the model. Humor styles clearly affected marital satisfaction among infertile couples (i.e., there was a positive relationship between humor and marital satisfaction). The fourth hypothesis (H4) that humor styles would predict high PA and low NA and was supported because the path analysis showed a positive correlation between humor, high PA, and low NA among infertile couples.

The findings here support the assertions of previous studies (Ford et al. 2016; Ko et al. 2007; Liu 2012; Ziv and Gadish 1989) claiming that individual's optimism and humor have an important and fundamental role in couples' marital satisfaction and affectivity. Joseph and Newman (2010) asserted that optimism has a strong role in the establishment and stabilization of marital satisfaction. Therefore, individuals with high levels of optimism are expected to show positive views concerning their marital relationship towards other people (Clark and Schroth 2010; Komarraju et al. 2009).

The results of the present study demonstrated that various factors play a role in creating marriage life satisfaction among infertile couples so that paying attention to them can play an

Table 6 Discriminant validity using Fornell-Larcker criteria

\begin{tabular}{lllll}
\hline & ASQ & HSQ & ENRICH & PANAS \\
\hline ASQ & 0.801 & & & \\
HSQ & 0.195 & 0.719 & 0.755 & 0.828 \\
ENRICH & 0.316 & 0.442 & 0.601 & \\
PANAS & 0.263 & 0.306 &
\end{tabular}


important role in facilitating good mental well-being concerning marriage. The findings of the present study support various previous findings in the literature (Cann and Collette 2014; Ghadami and Khalatbari 2015; Gorman and Jordan 2015; Homaei et al. 2016). The results indicated the importance of attention to the psychological health of infertile couples. In order to explain the role of optimism and humor upon marital satisfaction and affectivity, the findings here suggest that it is helpful to apply some aspects of marital satisfaction and affectivity affect status that can improve the experience of optimism and marital satisfaction among infertile couples. Thus, individuals who use optimism and humor strategies have an increased chance of achieving improved marital satisfaction, high PA, and low NA. Consequently, the findings here are presented to raise awareness for psychotherapists, health practitioners, and specific counselors who deal with infertile individuals undergoing medical treatment.

As with all studies, there are clearly limitations to the present one. The proposed model was only confirmed among a relatively small number of Iranian infertile couples. Therefore, it is necessary to test the model with larger sample sizes, longitudinal research, and carried out in different countries, as well as using qualitative methodologies to contribute further data to this work. One of the key limitations of the study concerned the demographics and personal characteristics such as the age, education, race, religion, type of infertility treatment, reproductive history, and main reason for infertility. The present results are based on infertile couple sample. Analysis of additional samples with different demographic profiles would increase the generalizability of the present findings. Another possible limitation is that the study used dyadic data and the observations were treated as independent. Because the analysis treated non-independent data as independent increases, there is the possibility of increasing type I errors (i.e., reporting false positives or at minimum overestimations of the relationships between the constructs). Based on the results here, the present authors suggest that psychological interventions or specific types of therapy such as interpersonal therapy and cognitive-behavior therapy by appropriate health practitioners may give relief to infertile couples by integrating adjunct therapies alongside medical treatments presented by professional infertility centers. Further research is needed to examine the model of the present study among other populations of infertile couples and individuals.

Acknowledgments The researchers wish to thank all the patients who participated and the staff of infertility centers that took part in this study.

\section{Compliance with Ethical Standards}

Conflict of Interest The authors declare that they have no conflict of interest.

Ethical Approval All the procedures carried out in the present study were in accordance with the Helsinki declaration and with the approval of the research team's institutional research committee. All participants were assured that their data were anonymous and confidential and that they could withdraw their participation at any time.

Informed Consent Informed consent was obtained from all participants.

Open Access This article is licensed under a Creative Commons Attribution 4.0 International License, which permits use, sharing, adaptation, distribution and reproduction in any medium or format, as long as you give appropriate credit to the original author(s) and the source, provide a link to the Creative Commons licence, and indicate if changes were made. The images or other third party material in this article are included in the article's Creative Commons licence, unless indicated otherwise in a credit line to the material. If material is not included in the article's Creative Commons licence and your intended use is not permitted by statutory regulation or exceeds the permitted use, you will need to obtain permission directly from the copyright holder. To view a copy of this licence, visit http://creativecommons.org/licenses/by/4.0/. 


\section{References}

Abbasi, A. R. K., Tabatabaei, S. M., Sharbaf, H. A., \& Karshki, H. (2016). Relationship of attachment styles and emotional intelligence with marital satisfaction. Iranian Journal of Psychiatry and Behavioral Sciences, $10(3), \mathrm{e} 2778$.

Ahmadi, H., Montaser-Kouhsari, L., Nowroozi, M. R., \& Bazargan-Hejazi, S. (2011). Male infertility and depression: A neglected problem in the Middle East. The Journal of Sexual Medicine, 8(3), 824-830.

Albort-Morant, G., Leal-Millán, A., \& Cepeda-Carrión, G. (2016). The antecedents of green innovation performance: A model of learning and capabilities. Journal of Business Research, 69(11), 4912-4917. https://doi.org/10.1016/j.jbusres.2016.04.052.

Ali, F., Rasoolimanesh, S. M., Sarstedt, M., Ringle, C. M., \& Ryu, K. (2018). An assessment of the use of partial least squares structural equation modeling (PLS-SEM) in hospitality research. International Journal of Contemporary Hospitality Management, 30, 514-538.

Alinia, K., Dousti, Y., Dehshiri, G., \& Heydari, M. (2009). Humor styles, subjective well-being, and emotional intelligence in college students. Journal of Iranian Psychologists, 5(18), 159-169.

Ashkani, F., \& Heydari, H. (2014). Effects of emotional adjustment on psychological welfare and attributional styles of students with learning disabilities in primary school. Journal of Learning Disabilities, 4(1), 6-22.

Becker, J.-M., Klein, K., \& Wetzels, M. (2012). Hierarchical latent variable models in PLS-SEM: Guidelines for using reflective-formative type models. Long Range Planning, 45(5-6), 359-394.

Becker, J.-M., Rai, A., Rigdon, E. (2013) Predictive validity and formative measurement in structural equation modeling: Embracing practical relevance. Thirty Fourth International Conference on Information Systems, Milan 2013.

Beltrán-Morillas, A. M., Valor-Segura, I., \& Expósito, F. (2019). Unforgiveness motivations in romantic relationships experiencing infidelity: negative affect and anxious attachment to the partner as predictors. Frontiers in Psychology, 10(434), 1-17.

Bowlby, J. (1969). Attachment and loss, Vol.1: Attachment. New York: Basic Books.

Bowlby, J. (1973). Attachment and loss, Vol. 2: Separation. New York: Basic Books.

Bowlby, J. (1979). The making and breaking of affectional bonds. London: Tavistock.

Bowlby, J. (1980). Attachment and loss, Vol. 3: Loss, sadness and depression. New York: Basic Books.

Cann, A., \& Collette, C. (2014). Sense of humor, stable affect, and psychological well-being. Europe's Journal of Psychology, 10(3), $464-479$.

Cassidy, J., Jones, J. D., \& Shaver, P. R. (2013). Contributions of attachment theory and research: A framework for future research, translation, and policy. Development and Psychopathology, 25(4 Pt 2), 1415-1434. https://doi.org/10.1017/S0954579413000692.

Clark, M. H., \& Schroth, C. A. (2010). Examining relationships between academic motivation and personality among college students. Learning and Individual Differences, 20(1), 19-24.

Faul, F., Erdfelder, E., Buchner, A., \& Lang, A.-G. (2009). Statistical power analyses using G* Power 3.1: Tests for correlation and regression analyses. Behavior Research Methods, 41(4), 1149-1160.

Ford, T. E., Lappi, S. K., \& Holden, C. J. (2016). Personality, humor styles and happiness: Happy people have positive humor styles. Europe's Journal of Psychology, 12(3), 320-337.

Fornell, C., \& Larcker, D. F. (1981). Evaluating structural equation models with unobservable variables and measurement error. Journal of Marketing Research, 18(1), 39-50.

Forooshany, S. H. A., Yazdkhasti, F., Hajataghaie, S. S., \& Esfahani, M. H. N. (2014). Infertile individuals' marital relationship status, happiness, and mental health: A causal model. International Journal of Fertility \& Sterility, 8(3), 315-324.

Foroozanfard, F., \& Sadat, Z. (2013). Diagnostic value of hysterosalpingography and laparoscopy for tubal patency in infertile women. Nursing and Midwifery Studies, 2(2), 188-192.

Fowers, B., \& Olson, D. (1993). ENRICH marital satisfaction scale: A reliability and validity study. Journal of Family Psychology, 7(2), 176-185.

Gana, K., \& Jakubowska, S. (2016). Relationship between infertility-related stress and emotional distress and marital satisfaction. Journal of Health Psychology, 21(6), 1043-1054.

Ghadami, E., \& Khalatbari, J. (2015). The relationship between optimism and resiliency and marital satisfaction among married students in Kerman University of Medical Sciences. International Research Journal of Social Science and Management, 2(1), 57-63.

Gharibi, M., Sanagouymoharer, G., \& Yaghoubinia, F. (2016). The relationship between quality of life with marital satisfaction in nurses in social security hospital in Zahedan. Global Journal of Health Science, 8(2), 178-184.

Gholami, R., Sulaiman, A. B., Ramayah, T., \& Molla, A. (2013). Senior managers' perception on green information systems (IS) adoption and environmental performance: Results from a field survey. Information \& Management, 50(7), 431-438. 
Gorman, G., \& Jordan, C. H. (2015). "I know you're kidding": Relationship closeness enhances positive perceptions of teasing. Personal Relationships, 22(2), 173-187.

Granqvist, P. (2014). Mental health and religion from an attachment viewpoint: overview with implications for future research. Mental Health, Religion and Culture, 17(8), 777-793.

Hair, J. F., Ringle, C. M., \& Sarstedt, M. (2011). PLS-SEM: indeed a silver bullet. Journal of Marketing Theory \& Practice, 19(2), 139-152.

Hair, J. F., Hult, G. T. M., Ringle, C. M., \& Sarstedt, M. (2017). A primer on partial least squares structural equation modeling (PLS-SEM) (2nd ed.). Thousand Oaks, CA: Sage.

Hair, J. F., Risher, J. J., Sarstedt, M., \& Ringle, C. M. (2019). When to use and how to report the results of PLSSEM. European Business Review, 31(1), 2-24.

Harzif, A. K., Santawi, V. P. A., \& Wijaya, S. (2019). Discrepancy in perception of infertility and attitude towards treatment options: Indonesian urban and rural area. Reproductive Health, 16(1), 126-126.

Hasanpoor, A. S., Simbar, Z., \& Vedadhir, A. (2014). The emotional-psychological consequences of infertility among infertile women seeking treatment: Results of a qualitative study. Iranian Journal of Reproductive Medicine, 12(2), 131-138.

Henseler, J., Ringle, C. M., \& Sarstedt, M. (2015). A new criterion for assessing discriminant validity in variancebased structural equation modeling. Journal of the Academy of Marketing Science, 43(1), 115-135.

Hills, P., \& Argyle, M. (2001). Happiness, introversion-extraversion and happy introverts. Personality and Individual Differences, 30(4), 595-608.

Homaei, R., Bozorgi, Z. D., Ghahfarokhi, M. S. M., \& Hosseinpour, S. (2016). Relationship between optimism, religiosity and self-esteem with marital satisfaction and life satisfaction. International Education Studies, 9(6), 53-61.

Hussein, A. (2014). Effect of psychological intervention on marital satisfaction rate of infertile couples. International Journal of Educational Policy Research and Review, 1(3), 28-36.

Inhorn, M. C., \& Patrizio, P. (2015). Infertility around the globe: New thinking on gender, reproductive technologies and global movements in the 21st century. Human Reproduction Update, 21(4), 411-426. https://doi.org/10.1093/humupd/dmv016.

Joseph, D. L., \& Newman, D. A. (2010). Emotional intelligence: An integrative meta-analysis and cascading model. Journal of Applied Psychology, 95(1), 54-78.

Ko, K. J., Berg, C. A., Butner, J., Uchino, B. N., \& Smith, T. W. (2007). Profiles of successful aging in middleaged and older adult married couples. Psychology and Aging, 22(4), 705-718.

Kobak, R. R., \& Hazan, C. (1991). Attachment in marriage: Effects of security and accuracy of working models. Journal of Personality and Social Psychology, 60(6), 861-869.

Komarraju, M., Karau, S. J., \& Schmeck, R. R. (2009). Role of the Big Five personality traits in predicting college students' academic motivation and achievement. Learning and Individual Differences, 19(1), 47-52.

Lindsay, T. J., \& Vitrikas, K. R. (2015). Evaluation and treatment of infertility. American Family Physician, 91(5), 308-314.

Liu, K. W. Y. (2012). Humor styles, self-esteem and subjective happiness. Humour, 1, 21-41.

Luk, B., \& Loke, A. Y. (2014). The impact of infertility on the psychological well-being, marital relationships, sexual relationships, and quality of life of couples: A systematic review. Journal of Sex \& Marital Therapy, 41(6), 610-625.

Macaluso, M., Wright-Schnapp, T. J., Chandra, A., Johnson, R., Satterwhite, C. L., Pulver, A., ... \& Pollack, L. A. (2008). A public health focus on infertility prevention, detection, and management. Fertility and Sterility, 93(1), 16.e11-16.e10.

Mahadeen, A., Mansour, A., Al-Halabi, J., Al Habashneh, S., \& Kenana, A. B. (2018). Psychosocial wellbeing of infertile couples in Jordan. East Mediterranian Health Journal, 24(2), 169-176.

Mardani Hamule, M., \& Heidari, H. (2010). The relationship between optimism and attachment styles with marital satisfaction in women. Nursing and Midwifery Journal, 8(1), 1-7.

Martin, R. A., \& Ford, T. (2018). The psychology of humor: An integrative approach. London: Academic Press.

Martin, R. A., Puhlik-Doris, P., Larsen, G., Gray, J., \& Weir, K. (2003). Individual differences in uses of humor and their relation to psychological well-being: Development of the Humor Styles Questionnaire. Journal of Research in Personality, 37(1), 48-75.

Mikulincer, M., Shaver, P. R., \& Pereg, D. (2003). Attachment theory and affect regulation: The dynamics, development, and cognitive consequences of attachment-related strategies. Motivation and Emotion, 27(2), 77-102.

Mirahmadi, S. L. (2009). Effect of short-time couple therapy with self-regulation method on optimism and couples happy of Esfahan city. Master's thesis. Esfahan University, Iran.

Mobarak Abadi, A., Fallahchai, R., \& Askari, M. (2014). The relationship between marital satisfaction and postpartum depression in women who visited health centers in Bandar Abbas city. Journal of Applied Environmental and Biological Sciences, 4(3), 120-124.

Moghadam, M., Rezaei, F., Ghaderi, E., \& Rostamian, N. (2016). Relationship between attachment styles and happiness in medical students. Journal of Family Medicine and Primary Care, 5(3), 593-599. 
Nasim, S., Bilal, S., \& Qureshi, M. (2019). Psycho-social aspects of infertility - a review of current trends. The Professional Medical Journal, 26(09), 1537-1541.

Noori, N., \& Biria, N. (2009). The relationship between natural optimism and optimistic views of Islam with life satisfaction. Journal of Psychology and Religion, 3(1), 29-68.

Parra, F., Miljkovitch, R., Persiaux, G., Morales, M., \& Scherer, S. (2017). The multimodal assessment of adult attachment security: Developing the Biometric Attachment Test. Journal of Medical Internet Research, 19(4), e100-e100.

Peterson, C., Park, N., Hall, N., \& Seligman, M. E. P. (2009). Zest and work. Journal of Organizational Behavior, 30(2), 161-172.

Peterson, C., Semmel, A., Von Baeyer, C., Abramson, L. Y., Metalsky, G. I., \& Seligman, M. E. (1982). The Attributional Style Questionnaire. Cognitive Therapy and Research, 6(3), 287-299.

Poursardar, F., Sangari, A., Abbaspour, Z., \& Alboukurdi, S. (2012). The effect of happiness on mental health and life satisfaction. Journal of Kerman University of Medical Sciences, 16(2), 139-147.

Raeisipoor, Z., Fallahchai, R., \& Zarei, E. (2012). The study of adult attachment styles, communication patterns, and marital satisfaction. Journal of Life Science \& Biomedicine, 3(1), 64-68.

Reinartz, W., Haenlein, M., \& Henseler, J. (2009). An empirical comparison of the efficacy of covariance-based and variance-based SEM. SSRN Electronic Journal. https://doi.org/10.2139/ssrn.1462666.

Ringle, C., Wende, S., \& Becker, J.-M. (2015). SmartPLS 3. Hamburg: University of Hamburg.

Rostami, M., Abolghasemi, A., \& Narimani, M. (2016). The effectiveness of quality of life therapy on quality of life in maladjustment couples. Pajouhan Scientific Journal, 15(1), 19-27.

Roudsari, R. L., \& Bidgoli, M. R. (2017). Collaborative infertility counseling and marital satisfaction in infertile females undergoing in-vitro fertilization: A randomized controlled trial. Nursing and Midwifery Studies, 6 , $1-7$.

Sabouripour, F., \& Roslan, S. B. (2015). Resilience, optimism and social support among international students. Asian Social Science, 11(15), 159-170.

Safari, R. (2016). Evaluating the relationship between humor styles and marital satisfaction among education ministry staffs in Sari. The Social Sciences, 11(9), 2362-2366.

Sami, N., Ali, T. S., Wasim, S., \& Saleem, S. (2012). Risk factors for secondary infertility among women in Karachi, Pakistan. PLoS One, 7(4), e35828.

Saroglou, V., Lacour, C., \& Demeure, M.-E. (2010). Bad humor, bad marriage: Humor styles in divorced and married couples. Europe's Journal of Psychology, 6(1), 94-121.

Sarstedt, M., Ringle, C. M., \& Hair, J. F. (2017). Partial least squares structural equation modeling. Handbook of Market Research, 26, 1-40.

Scheier, M. F., \& Carver, C. S. (1985). Optimism, coping, and health: Assessment and implications of generalized outcome expectancies. Health Psychology, 4(3), 219-247.

Seligman, M. (2006). Learned optimism: How to change your mind and your life. London: Vintage.

Shakerian, A. (2010). Evaluation of the factors influencing marital satisfaction in the students of Islamic Azad Uiversity in Sanandaj. Scientific Journal of Kurdistan University of Medical Sciences, 14(4), 40-49.

Smith, P., Caputi, P., \& Crittenden, N. (2013a). Measuring optimism in organizations: Development of a Workplace Explanatory Style Questionnaire. Journal of Happiness Studies, 14(2), 415-432. https://doi. org/10.1007/s10902-012-9336-4.

Smith, T. W., Ruiz, J. M., Cundiff, J. M., Baron, K. G., \& Nealey-Moore, J. B. (2013b). Optimism and pessimism in social context: An interpersonal perspective on resilience and risk. Journal of Research in Personality, 47(5), 553-562. https://doi.org/10.1016/j.jrp.2013.04.006.

Sohl, S. J., Moyer, A., Lukin, K., \& Knapp-Oliver, S. K. (2011). Why are optimists optimistic? Individual Differences Research, 9(1), 1-11 Retrieved from https://pubmed.ncbi.nlm.nih.gov/23239937.

Turliuc, M., \& Candel, O. (2017). Ideal standards, optimism and couple satisfaction among Romanian couples: Actor, partner and similarity effects. Psihologia Socială, 40(1), 83-96.

Vahidi, S., Ardalan, A., \& Mohammad, K. (2009). Prevalence of primary infertility in the Islamic Republic of Iran in 2004-2005. Asia-Pacific Journal of Public Health, 21(3), 287-293.

Vander Borght, M., \& Wyns, C. (2018). Fertility and infertility: Definition and epidemiology. Clinical Biochemistry, 62, 2-10.

Vizheh, M., Pakgohar, M., Babaei, G., \& Ramezanzadeh, F. (2013). Effect of counseling on quality of marital relationship of infertile couples: A randomized, controlled trial (RCT) study. Archives of Gynecology and Obstetrics, 287(3), 583-589.

Vollmann, M., Sprang, S., \& van den Brink, F. (2019). Adult attachment and relationship satisfaction: The mediating role of gratitude toward the partner. Journal of Social and Personal Relationships, 36(11-12), 3875-3886. 
Voorhees, C. M., Brady, M. K., Calantone, R., \& Ramirez, E. (2016). Discriminant validity testing in marketing: An analysis, causes for concern, and proposed remedies. Journal of the Academy of Marketing Science, 44, $119-134$.

Watson, D., Clark, L., \& Tellegen. (1988). Development and validation of brief measures of positive and negative affect: The PANAS scales. Journal of Personality and Social Psychology, 54(6), 1063-1070.

Wróbel, M., Finogenow, M., Szymańska, P., \& Laurent, J. (2019). Measuring positive and negative affect in a school-based sample: A Polish version of the PANAS-C. Journal of Psychopathology and Behavioral Assessment, 41, 598-611.

Zaheri, F., Dolatian, M., Shariati, M., Simbar, M., Ebadi, A., \& Azghadi, S. B. H. (2016). Effective factors in marital satisfaction in perspective of Iranian women and men: A systematic review. Electronic Physician, 8(12), 3369-3377.

Ziv, A., \& Gadish, O. (1989). Humor and marital satisfaction. Journal of Social Psychology, 129(6), 759-768.

Publisher's Note Springer Nature remains neutral with regard to jurisdictional claims in published maps and institutional affiliations. 